\title{
Article
}

\section{The South Korean Twin Registry}

\author{
Yoon-Mi Hur ${ }^{1}$, Man Chull Kang ${ }^{1}$, Hoe-Uk Jeong ${ }^{1}$, Il Cook Kang ${ }^{1}$ and Jong Woo Kim² \\ ${ }^{1}$ Institute for Education Research, Department of Education, Mokpo National University, Jeonnam, South Korea and ${ }^{2}$ Department of Neuropsychiatry, Kyung Hee \\ University, Seoul, South Korea
}

\begin{abstract}
The South Korean Twin Registry (SKTR) is an ongoing nationwide volunteer registry of South Korean twins and their families. Since its inception, from preschooler to young adult, twins have been registered with the SKTR and have demonstrated that relative influences of genetic and environmental factors explaining individual differences in various psychological, mental health and physical traits in South Koreans are similar to those found in many Western twin studies. Currently, studies at the SKTR focus on identification of the process of gene-by-environment interactions as well as developmental differences in genetic and environmental influences on psychological and mental health traits in South Koreans. This report provides a brief overview, recruitment strategies, current samples, zygosity assessment, measures and future directions of the SKTR.
\end{abstract}

Keywords: South Korea Twin Registry; development; psychological traits; mental health

(Received 19 July 2019; accepted 6 August 2019; First Published online 26 December 2019)

The South Korean Twin Registry (SKTR) is an ongoing nationwide volunteer registry of South Korean twins and their families. The general goal of the SKTR is to understand the interplay of genetic and environmental influences on psychological and mental health traits in South Koreans. Since its inception, multiple cross-sectional twin studies that span preschool age to early adulthood have been conducted (Hur, 2002; Hur et al., 2006, 2013). Relative influences of genetic and shared environmental factors in many psychological, mental health and physical traits found in these studies were similar to those reported in Western twin samples, although absolute phenotypic, genetic and environmental variances were found to be different to those discovered in Western samples (Hur et al., 2008), suggesting that further analyses are necessary to determine genetic and environmental etiologies of variations across human populations. Current major research issues of the SKTR include detection of environmental variables that interact with genetic factors as well as identification of the process of gene-by-environment interaction in psychological and mental health in children and adolescents. Recently, we have also begun exploring genetic influences on mental health unique to South Koreans, such as hwabyung (anger syndrome), which most Korean mental health professionals and the layperson have assumed to be environmental in origin (Hur, Choi et al., 2018; Hur, Jin, Lee, et al., 2019. The SKTR has been a partner contributing to the international consortiums such as the Cohort Description of Collaborative Project of Development of Anthropometrical Measures in Twins (CODATwins; Silventoinen et al., 2019) and is ready to serve as other international collaborations to identify genetic and environmental origins of human psychological and health traits.

Author for correspondence: Yoon-Mi Hur, Email: ymhur@mokpo.ac.kr

Cite this article: Hur Y-M, Kang MC, Jeong H-U, Kang IC, and Kim JW. (2019) The South Korean Twin Registry. Twin Research and Human Genetics 22: 606-608, https:// doi.org/10.1017/thg.2019.115

\section{Recruitment Strategies}

We identify twins mainly from schools, large maternity hospitals and the websites of the twins' mothers' clubs throughout South Korea. We ask city and provincial education offices to send our invitation letters to each school to obtain contact information (typically, telephone number) of twins interested in participation in our research. In addition, we obtain contact information about mothers of twins from large maternity hospitals. Once we receive contact information, our trained research staff telephone twins or mothers of twins, explain our research in detail and then give telephone interviews. We also advertise our research on the websites of twins' mothers' clubs. Typically, we attach online questionnaires to the websites and ask mothers of twins to complete the questionnaire online.

\section{Sample and Zygosity Assessment}

Table 1 presents the number of individual twins who have been participated in studies of the SKTR by age group and zygosity. Because residents in large cities in South Korea move around quite often, we have lost the contact information of twins during the past years. To supplement the registry membership, however, we have recruited new volunteer twins whenever fund is available.

While opposite-sex twins in the SKTR are automatically assigned to dizygotic (DZ) twins, same-sex twins complete a three-item zygosity questionnaire to determine their zygosity. For twins under age 13, we ask mothers of twins to complete the zygosity questionnaire, whereas for twins aged 13 years or older, we ask twins to complete the zygosity questionnaire. For preschool-aged twins ascertained from maternity hospitals, information on chorionicity of twins is additionally used to determine zygosity. As indicated in Table 1, while monozygotic (MZ) twins outnumbered DZ twins in both

(c) The Author(s) 2019. This is an Open Access article, distributed under the terms of the Creative Commons Attribution-NonCommercial-NoDerivatives licence (http://creativecommons. org/licenses/by-nc-nd/4.0/), which permits non-commercial re-use, distribution, and reproduction in any medium, provided the original work is unaltered and is properly cited. The written permission of Cambridge University Press must be obtained for commercial re-use or in order to create a derivative work. 
Table 1. Number ${ }^{\mathrm{a}}$ of twins participated in studies of the South Korean Twin Registry by age group and zygosity

\begin{tabular}{lcccr}
\hline Age group & Age & MZ & DZ $^{\text {b }}$ & Total \\
\hline Preschoolers & $<7$ years & 257 & 625 & 882 \\
\hline School-aged children & $7-18$ years & 995 & 686 & 1681 \\
\hline Young adults & $>19$ years & 949 & 546 & 1495 \\
\hline Total & & 2201 & 1857 & 4058 \\
\hline
\end{tabular}

Note: $\mathrm{MZ}=$ monozygotic twins; $\mathrm{DZ}=$ dizygotic twins.

${ }^{a}$ Number of twin individuals.

bopposite-sex DZ are included.

the school-aged and young adult groups, the number of DZ twins is much greater than $\mathrm{MZ}$ twins in the preschooler group, which reflects recent changes of DZ twin birth rates in South Korea (Hur \& Kwon, 2005; Hur \& Song, 2009).

\section{Measures}

The instruments used for studies of the SKTR have been selected for their high psychometric properties and compatibilities with other twin studies in the world. Assessment categories of the SKTR include childhood temperament, personality, cognitive abilities, problem behaviors and mental health, family physical and psychological environment, and physical traits. To measure childhood temperament, the Emotionality, Activity, and Sociability scale (Buss \& Plomin, 1984) has been used for mothers of preschooler twins (Hur, 2009a; Veselka et al., 2012). The Eysenck Personality Scale (Eysenck \& Eysenck, 1991), grit (Duckworth \& Quinn, 2009) and economic behavior have been used with adolescent and young adult twins for personality assessment (Hur, 2007a; Hur et al., 2011; Rushton et al., 2008, 2009). The Standard Progressive Matrices-Plus version (Raven, 2008) has been used for assessment of cognitive abilities for school-aged twins. To measure problem behaviors and mental health traits, the Strengths and Difficulties Questionnaire (Goodman, 1997), hostility (Koskenvuo et al., 1988), Launey-Slade Hallucination Scale - Revised (Launay \& Slade,1981), clinical symptoms of Personality Assessment Inventory (Morey, 1991), Center for Epidemiological Studies-Depression scale (Radloff, 1977), and Maudsley Obsessive-Compulsive Inventory (Hodgson \& Rachman, 1977), and hwabyung (anger syndrome), have been administered to adolescent and young adult twins (Hur, 2006, 2007b, 2008, 2009b, 2014, 2015; Hur et al., 2015; Hur, Cherny et al., 2012; Hur, Choi et al., 2018; Hur \& Jeong, 2008; Hur, Jin, Lee et al., 2019; Hur \& Rushton, 2007). To assess physical and psychological family environment, the Family Asset Questionnaire and the Family Adaptability and Cohesion Scale (Olson et al., 1985) have been administered to twins or parents of twins. For physical traits, height, weight, birth weight and Sasang constitution types have been obtained either through parental report or self-report for most twins. In addition, pubertal timing (Hur, 2007c; Hur, Jin, \& Lee, 2019; Hur, Lee, \& Jin, 2018; Hur \& Shin, 2008; Hur et al., 2005, 2008) and cold hands symptoms (Hur, Chae et al., 2012; Hur, Jin et al., 2018; Hur, $\mathrm{Yu}$ et al., 2018) have been collected from adolescent and young adult twins.

\section{Future Directions}

To date, the vast majority of twin studies have been conducted in Australia, Europe and the USA, although more recently, they have been extended to non-Western countries. As one of only several twin registries in Asia, the SKTR has published over 50 research papers in international scientific journals, enhancing our understanding of human population differences and similarities in genetic architectures of complex traits.

Traditionally, twins were uncommon in South Korea (Hur \& Kwon, 2005). However, recently, the DZ twin birth rates have increased very sharply in South Korea due to the widespread use of artificial reproductive technology (Hur \& Song, 2009). We thus have the potential to add a substantial number of new twins each year to the registry. In the future, we plan to investigate how genetics exert their influences on treatment outcomes and effects of intervention in problem behaviors and mental health traits in South Koreans. Additionally, efforts will be made to identify polymorphisms associated with the psychological and mental health traits in South Koreans.

Acknowledgements. We would like to thank twins and their families and many research assistants who participated in the SKTR. The SKTR has been supported by National Research Foundation grants in Korea (NRF-2001041-C00548, NRF-2008-327-B00003, NRF-2011-371-B00047), Pioneer Fund (USA) and Korea Institute of Oriental Medicine (K18092; K18095).

\section{References}

Buss, A. H., \& Plomin, R. (1984). Temperament: Early developing personality traits. Hillsdale, NJ: Erlbaum.

Duckworth, A. L., \& Quinn, P. D. (2009). Development and validation of the Short Grit Scale (GfRIT-S). Journal of Personality Assessment, 91, 166-174.

Eysenck, H. J., \& Eysenck, S. B. G. (1991). Manual of the Eysenck personality scales. London: Hodder \& Stoughton.

Goodman, R. (1997). The strengths and difficulties questionnaire: A research note. Journal of Child Psychology and Psychiatry, 38, 581-586.

Hodgson, R. J., \& Rachman, S. (1977). Obsessional-compulsive complaints. Behavior Research and Therapy, 15, 389-395.

Hur, Y.-M. (2002). Seoul twin family study: Design, sampling, assessments, and future directions. Twin Research, 5, 389-393.

Hur, Y.-M. (2006). Nonadditive genetic effects on hostility in South Korean adolescent and young adult twins. Twin Research and Human Genetics, 9, 637-654.

Hur, Y.-M. (2007a). Evidence for nonadditive genetic effects on Eysenck Personality Scales in South Korean twins. Twin Research and Human Genetics, 10, 373-378.

Hur, Y.-M. (2007b). Effects of the chorion type on prosocial behavior in young twins. Twin Research and Human Genetics, 10, 773-777.

Hur, Y.-M. (2007c). Sex difference in heritability of BMI in South Korean adolescent twins. Obesity, 15, 2908-2911.

Hur, Y.-M. (2008). Sex differences in genetic and environmental contributions to depression symptoms in South Korean adolescent and young adult twins. Twin Research and Human Genetics, 11, 306-313.

Hur, Y.-M. (2009a). Genetic and environmental contributions to childhood temperament in South Korean twins. Twin Research and Human Genetics, 12, 549-554.

Hur, Y.-M. (2009b). Genetic and environmental contributions to the covariations between obsessive-compulsive symptoms, neuroticism, and extraversion. Twin Research and Human Genetics, 12, 142-149.

Hur, Y.-M. (2014). Increasing phenotypic and genetic variations in hyperactivity/ inattention problems from age 3 to13 years: A cross-sectional twin study. Twin Research and Human Genetics, 17, 545-552.

Hur, Y.-M. (2015). Genetic and environmental etiology of the relationship between childhood hyperactivity/inattention and conduct problems in a South Korean twin sample. Twin Research and Human Genetics, 18, 290-297.

Hur, Y.-M., Chae, J.-H., Kim, J. J., Jeong, H.-U., Kim, J. W., Seo, S. Y., \& Kim, K. S. (2012). Feeling of cold hands and feet is a highly heritable phenotype. Twin Research and Human Genetics, 15, 166-169.

Hur, Y.-M., Cherny, S. S., \& Sham, P. C. (2012). Heritability of hallucination in adolescent twins. Psychiatry Research, 199, 98-101. 
Hur, Y.-M., Choi, E.-J., Kim, J.-W., Jin, H.-J., \& Lee, S. (2018). Heritability of Hwabyung symptoms in South Korean adolescent and young adult twins. Twin Research and Human Genetics, 21, 378-383.

Hur, Y.-M., Hwang, S., \& Chung, U.-S. (2015). Increasing relationship between negative emotionality and conduct problems during childhood: A cross-sectional behavioral genetic analysis. Twin Research and Human Genetics, 18, 785-792.

Hur, Y.-M., \& Jeong, H.-U. (2008). Sex differences in genetic and environmental influences on obsessive-compulsive symptoms in South Korean adolescent and young adult twins. Twin Research and Human Genetics, $11,314-320$.

Hur, Y.-M., Jeong, H.-U., Chung, K. W., Shin, J. S., \& Song, T. B. (2013). The South Korean Twin Registry: an update. Twin Research and Human Genetics, 16, 237-240.

Hur, Y.-M., Jeong, H.-U, Schermer, J., \& Rushton, J. P. (2011). Miserliness is heritable. Personality and Individual Differences, 51, 1052-1055.

Hur, Y.-M., Jin, H.-J., \& Lee, S. (2018). Etiologies of the relationships among body mass index and cold-heat patterns: A twin study. Twin Research and Human Genetics, 2, 233-238.

Hur, Y.-M., Jin, H.-J., \& Lee, S. (2019). Heritability of age at menarche in South Korean female twins. Twin Research and Human Genetics, 22, 183-186.

Hur, Y.-M., Jin, H.-J., Lee, S., \& Kim, J.-W. (2019). Shared genetic etiology of Hwabyung (anger syndrome) and somatization symptoms in South Korean adolescent and young adult twins. Twin Research and Human Genetics, 22, 114-119.

Hur, Y.-M., Kaprio, J., Iacono, W. G., Boomsma, D. I., McGue, M., Silventoinen, K., \& Mitchell, K. (2008). Genetic influences on the difference in variability of height, weight and body mass index between Caucasian and East Asian adolescent twins. International Journal of Obesity, 32, 1455-1467.

Hur, Y.-M., \& Kwon, J. S. (2005). Changes in twinning rates in South Korea: 1981-2002. Twin Research and Human Genetics, 8, 76-79.

Hur, Y.-M., Lee, S., \& Jin, H.-J. (2018). Genetic and environmental overlaps among Sasang Constitution Types: A multivariate twin Study. Twin Research and Human Genetics, 21, 518-526.

Hur, Y.-M., Luciano, M., Martin, N. G., Boomsma, D. I., Iacono, W. G., McGue, M., \& Han, J. Y. (2005). A comparison of twin birth weight data from Australia, the Netherlands, the United States, Japan, and South Korea: Are genetic and environmental variations in birth weight similar in Caucasians and East Asians? Twin Research and Human Genetics, 8, 638-648.

Hur, Y.-M., \& Rushton, J. P. (2007). Genetic and environmental contributions to prosocial behavior in 2- to 9- year-old South Korean twins. Biology Letters, $3,664-666$.
Hur, Y.-M., \& Shin, J. (2008). Effects of chorion type on genetic and environmental influences on height, weight, and body mass index in South Korean young twins. Twin Research and Human Genetics, 11, 63-69.

Hur, Y.-M., Shin, J., Jeong, H-U., \& Han, J. Y. (2006). The South Korean Twin Registry. Twin Research and Human Genetics, 9, 838-843.

Hur, Y.-M., \& Song, T.-B. (2009). A recent rise in twin birth rates and demographic changes in mothers of twins in South Korea: 2003-2007. Twin Research and Human Genetics, 12, 118-122.

Hur, Y.-M., Yu, H., Jin, H.-J., \& Lee, S. (2018). Heritability of cold and heat patterns: A twin study. Twin Research and Human Genetics, 21, 227-232.

Koskenvuo, M., Kaprio, J., Rose, R. I., Kesaniemi, A., Sara, S., \& Heikkila, K. (1988). Hostility as a risk factor for mortality and ischemic heart disease in men. Psychosomatic Medicine, 50, 330-340.

Launay, G., \& Slade, P. D. (1981). The measurement of hallucinatory predisposition in male and female prisoners. Personality and Individual Differences, 2, 221-234.

Morey, L. C. (1991). Personality Assessment Inventory, professional manual. Lutz, FL: Personality Assessment Resources.

Olson, D. H., Portner, J., \& Lavee, Y. (1985). FACES III. St. Paul, MN: Family Social Science, University of Minnesota.

Radloff, L. S. (1977). The CES-D scale: A self-report depression scale for research in the general population. Applied Psychological Measures, 1, 385-401.

Raven, J. (2008). Standard progressive matrices-plus version and Mill Hill Vocabulary Scale. Manual. London: Pearson.

Rushton, J. P., Ann Bons, T., Ando, J., Hur, Y.-M., Irwing, P., Vernon, P. A., .. Barbaranelli, C. (2009). A general factor of personality from multitraitmultimethod data and cross national twins. Twin Research and Human Genetics, 12, 356-365.

Rushton, J. P., Ann Bons, T., \& Hur, Y.-M. (2008). The genetics and evolution of the general factor personality. Journal of Research in Personality, 42, 1173-1183.

Silventoinen, K., Jelenkovic, A., Yokoyama, Y., Sund, R., Sugawara, M., Tanaka, M., \& Kaprio, J. (2019). The CODATwins Project: The current status and recent findings of COllaborative Project of Development of Anthropometrical Measures in Twins. Twin Research and Human Genetics. Advance online publication. doi: 10.1017/thg.2019.35.

Veselka, V., Schermer, J. A., Just, C., Hur, Y-M., Rushton, J. P., Jeong, H-U., \& Vernon, P. A. (2012). Emotion and behavior: A general factor of personality from the EAS Temperament Survey and the Strengths and Difficulties Questionnaire. Twin Research and Human Genetics, 15, 668-671. 